\title{
The State of Water Supply and Sanitation in Government Primary Schools in Dares Salaam Region a Case of Kinondoni Municipality
}

\author{
Mafuru Solomi Juma ${ }^{1}$, Peter Elia Mosha ${ }^{2}$, Stanslaus Mbonea Msuya ${ }^{1}$ \\ ${ }^{1}$ Department of Environmental Planning, Institute of Rural Development Planning, Dodoma, Tanzania \\ ${ }^{2}$ Department of Population Studies, Institute of Rural Development Planning, Dodoma, Tanzania
}

Email address:

mjuma@irdp.ac.tz (M. S. Juma), pmosha@irdp.ac.tz (P. E. Mosha), smsuya@irdp.ac.tz (S. M. Msuya)

\section{To cite this article:}

Mafuru Solomi Juma, Peter Elia Mosha, Stanslaus Mbonea Msuya. The State of Water Supply and Sanitation in Government Primary Schools in Dares Salaam Region A Case of Kinondoni Municipality. Frontiers in Environmental Microbiology.

Vol. 4, No. 3, 2018, pp. 84-87. doi: 10.11648/j.fem.20180403.11

Received: March 6, 2018; Accepted: April 9, 2018; Published: May 9, 2018

\begin{abstract}
This paper sets out to assess the state of water supply and sanitation in government primary schools in Kinondoni Municipality. It based on data collected in 2013. A cross-sectional study design was adopted, collecting data through the use of questionnaire, in-depth interviews and observation from ten public primary schools in the study area. Statistical Package for social science (SPSS) was used to clean and analyse the data collected. The study found out that there is inadequate and unreliable water supply, water storage facilities and shortage of functioning hand-washing facilities. The available sanitation facilities are poorly utilized due to various reasons including pupils' background personal hygiene, sanitation technology, pupils' population, lack of hygiene education and school weakness in implementing School Water, Sanitation and Hygiene (SWASH) guideline. The study concludes that although the government primary schools in Kinondoni Municipality own a variety of water sources and sanitation facilities, generally there is inadequate coverage of water and sanitation facilities in primary schools. Also the SWASH guidelines did not specify who is to be responsible for the maintenance costs, awareness creation to teachers, parents, and pupils as well cultural aspect on the use of SWASH facilities were not considered. To increase water reliability at schools, multiple sources (water tape and deep wells) could be the best solution. Parents and pupils should be involved in SWASH program awareness and consider economic (maintenance costs) and cultural appropriateness, also to avoid punishing pupils by using toilet cleaning at schools.
\end{abstract}

Keywords: Sanitation, Hygiene, Hand Washing

\section{Introduction}

The challenges of School Water, Sanitation and Hygiene (SWASH) are more pronounced in developing countries unlike the developed world. According to the [12]; in sixty (60) countries in the developing world, more than half of primary schools had shortage of water facilities and nearly two thirds did not have adequate sanitation. The majority of primary schools in the developing world lack the basic amenities of water supply, sanitation and hygiene education (SWASH) for pupils and teachers. Diseases caused by unsafe drinking water and inadequate sanitation remain Africa's most serious public health threat, causing $80 \%$ of sicknesses and killing 5,000 children every day [2]. The lack of clean drinking water and proper toilet facilities undermines the sustainability of other critical needs, including education, economic development, nutrition, environmental health and gender equality $[9,26,23]$.

For many years now, sanitation has become an international policy agenda whereby in 2002, it was included in the Millennium Development Goals (MDGs) that ended in 2015. The MDG No. $7 \mathrm{C}$ targeted to reduce by half the proportion of people without basic sanitation by 2015 [10]. In its effort to speed up progress towards realizing the goal in 2006 the UN declared year 2008 'The International Year of Sanitation' [6, 15, 8]. Furthermore in 2010, the United Nations General Assembly included sanitation on the list of human rights $[5,8]$.

However, the WHO and UNICEF judges MDG Goal 7, 
Target $7 \mathrm{c}$ that it has failed in achieving the expected results, although more than 2.1 billion people have gained access to improved sanitation worldwide, yet 2.4 billion people have no access to improved sanitation facilities, including 946 million people who practice open defecation [25, 8]. Likewise, according to UNICEF, (2017) about 2.4 billion people worldwide had no access to improved sanitation and 663 million people had no access to improved water sources. Although, the MDGs target for sanitation was not achieved, the UN did not remain silent; instead they included sanitation as goal 6 in the 2030 agenda for Sustainable Development commonly known as SDGs [11]. Using its own words the UN set ambitious and transformational vision among other things it demanding; "...A world with equitable and universal access to quality education at all levels... A world where we reaffirm our commitments regarding the human right to safe drinking water and sanitation and where there is improved hygiene and sanitation facilities [11 - 7]". The goal 6 specifically wants to "ensure availability and sustainable management of water and sanitation for all [11-18]". At the same time the SDGs goal 4 and 5 propagate "inclusive and quality education and gender equality for all "respectively. In this sense schools as training institutions have big role to play to ensure sustainable management of water and sanitation in any country. It is in such training institutions where teaching is done, and thus creating possibility for a multiplier effect through transmission to the community the learned good practices for water and sanitation management [7, 26, 23]. Young, (2017) argue that the expected multiplier effect in developing countries may not be achieved due to poor WASH coverage. Poor WASH conditions and repeatedly pupils falling sick due to water and sanitation problems have impact to child health, cognitive, social development including IQ, school performance, working memory and behaviuoral problems [1, 23, 26].

In most parts of Tanzania, pupils experience high rates of communicable diseases due to poor sanitation and unhygienic behaviours. A study conducted by SNV, Water Aid and UNICEF in 2010 in 16 districts covering 2697 schools in Tanzania mainland, revealed that $6 \%$ of the schools had no latrines, $84 \%$ had no hand washing facilities, and $38 \%$ of the schools had no water supply [14].

The Primary Education Development Programme (PEDP), Secondary Education Development Programme (SEDP) accompanied by government decision to make primary education free for all have led to the increased enrollment of children in schools $[17,20]$. This increase has mounted a huge demand for facilities particularly classrooms, chairs, laboratories, latrine and water supply. Unfortunately, water and latrine facilities did not receive equal attention like others. As a result the situation of WASH continues to deteriorate $[9,17,7]$.

The increase of school enrolment since 2002 has put a heavy burden on existing school infrastructure and particularly on WASH facilities, which generally were already suffering from poor operation and maintenance. [2] reported that, the World Health Organization (WHO) tasked the National governments to "ensure that every child has access to Hygiene, Sanitation and Water (HSW) in school and that no new schools are constructed without HSW facilities". This has not been the case, as many new schools and classrooms are built with no consideration for WASH facilities or if built, these rarely follow any standards $[1,22$, 26]. The provision of safe water and sanitation facilities in schools is a first step towards a healthy physical learning environment, benefiting both learning and health $[1,26]$. However, the mere provision of facilities does not necessarily make them sustainable or produce the desired impact. It is the use of latrines and the related appropriate hygiene behaviour of people that provides health benefits [11, 23]. Poor state of water supply and sanitation facilities in schools is a major factor for the declining of pupils' class attendance and their ability to learn $[9,23,26]$. The water supply and sanitation conditions of schools have become a public health concern in recent years $[22,20]$.

\section{Methods}

\subsection{Study Area}

Data were collected between March and July 2013 in 10 primary schools of the then Kinondoni Municipality (now Kinondoni and Ubungo Municipalities). In 2015 the government of Tanzania subdivided Kinondoni Municipality into two Municipalities of Kinondoni and Ubungo. This may have effects on population of Kinondoni Municipality as well as the number of primary schools. The population of the then Kinondoni Municipality was $1,775,049$ people as reported by 2012 population census [18]. Kinondoni municipality by then had total of 138 government primary schools.

\subsection{Study Design and Data Collection}

The study adopted a cross-sectional design. Both quantitative and qualitative data were collected from primary sources whereby pupils, teachers and key informants were interviewed. The collected primary data were supported by secondary data collected from the schools and from the Municipal directors' office. Interview and observation were the main data collection methods used. Tools used for data collection in this study were structured questionnaire for pupils; checklist was used for indepth interview with selected teachers and to guide observation. The study used individual, as a sampling unity whereby, a total of 351 respondents were interviewed among them 330 were pupils, 20 were teachers and 1 district health officer. The 10 primary schools in Table 1 that were used for this study were randomly selected. The study opted to take equal number of pupils (i.e 33 pupils) from each selected school whereby simple random sampling was used to pick pupils who participated in the study from class 4, 5,6 and 7. Pupils from these classes were chosen because they have been in school for at least three years and therefore they have knowledge on the state of water supply and sanitation facilities of their schools. The ten Head teachers and ten health teachers for the in-depth interviews were purposively selected from the ten primary schools because of the positions they hold in schools. 
Table 1. Distribution of Primary schools, Pupils and Teachers in Kinondoni municipalit.

\begin{tabular}{|c|c|c|c|c|c|c|c|c|}
\hline $\mathbf{S} / \mathbf{N}$ & Name of school & Ward & Boys & Girls & Total & Male teachers & Female teachers & Total \\
\hline 1 & Makongo & Makongo & 579 & 588 & 1167 & 2 & 32 & 34 \\
\hline 2 & Tegeta A & Goba & 581 & 740 & 1321 & 4 & 17 & 21 \\
\hline 3 & Shekilango & $\mathrm{K} /$ nyama & 188 & 223 & 411 & 2 & 22 & 24 \\
\hline 4 & Manzese & Manzese & 953 & 897 & 1850 & 6 & 52 & 58 \\
\hline 5 & Mabibo & Makuburi & 530 & 684 & 1115 & 7 & 37 & 44 \\
\hline 6 & Kawawa & Mabibo & 1449 & 1475 & 2924 & 9 & 56 & 65 \\
\hline 7 & Kimara Baruti & Kimara & 621 & 698 & 1319 & 4 & 53 & 57 \\
\hline 8 & Kawe A & Kawe & 850 & 886 & 1736 & 8 & 39 & 47 \\
\hline 9 & Tandale & Tandale & 877 & 932 & 1809 & 8 & 38 & 46 \\
\hline 10 & Mlimani & Ubungo & 495 & 511 & 1006 & 7 & 45 & 52 \\
\hline
\end{tabular}

\subsection{Data Analysis}

Collected data were coded and entered into SPSS version 20 for analysis. Main analysis done was descriptive analysis including running frequencies, computing means and standard deviations. Cross tabulations and tables were also used.

\section{Results and Discussion}

\subsection{State of Water Supply Facilities in Kinondoni Municipality}

The concept of water supply in urban areas and specifically in primary schools is well defined in education for all 2015 national review report as well in the National Strategic Plan for School Water, Sanitation and Hygiene (SWASH) of years 2012 to 2017 [17, 19].

\subsubsection{Water Source and Distances}

According to SWASH guideline (2010) all school should have a protected water source within their premises [17]. Water source (such as shallow wells) must be at least 50 meters away from the toilets or wastewater sources or drainage depending on soil condition of the area. From the data collected it was revealed that $40 \%$ of primary schools obtained their water from piped sources, $10 \%$ had boreholes with electrical pump while $10 \%$ of schools reported having rainwater harvesting within the school compound and $40 \%$ of the sampled schools had no any water sources. Most of the water sources were found within the government recommended distance (400meters) from the school. However, those water sources were not adequate and reliable water supply for pupils in schools. In agreement with these findings a study conducted jointly by WaterAid Tanzania and UNICEF in 2009 that reported poor state of water supply and sanitation facilities in schools [21]. It is recognized that actual level of consumption of water depends on several factors, the main one being convenience of the supply for which distance traveled is one of the determinants. It was revealed that school sanitation facilities that are far away may discourage their use $[1,4,2,8]$.

\subsubsection{Treatment of Water Source}

Despite the percentage of schools with piped water access, many of these sources were not functioning. $75 \%$ of sampled schools reported that their main water sources were treated, but this figure is based on school responses not from water quality analysis. Reviewed from the literature it is recommended that water supplied to schools should be of drinking water quality that must be frequently checked $[17$, 19]. Basically, school children and staff require 5 liters per person per day in day schools and 20 liters per person per day for all residential school children and staff in boarding schools $[24,19]$. Although all schools that were visited were day schools that required 5 litres per day per person but they all had water shortage as shown in Table 2. Six schools had no water supply and this was taken for granted because some of pupils and teachers brought drinking water from home and sometimes they use unsafe sources or buy from nearby shops. The situation was not good for pupils because most of time they don't care to use untreated water $[1,3]$.

Table 2. Quantification of water demand needed for each school.

\begin{tabular}{|c|c|c|c|c|c|c|}
\hline $\mathbf{S} / \mathbf{N}$ & Name of school & Total population & $\begin{array}{l}\text { Estimated Water } \\
\text { demand in (liters/d) }\end{array}$ & $\begin{array}{l}\text { Available water } \\
\text { (liters/d) }\end{array}$ & $\begin{array}{l}\text { Water deficit } \\
\text { (liters/d) }\end{array}$ & Deficit in Percentage \\
\hline 1 & Makongo & 1167 & 7,002 & & 7,002 & 100 \\
\hline 2 & Tegeta A & 1323 & 7,938 & & 7,938 & 100 \\
\hline 4 & Manzese & 1850 & 11,100 & 9,250 & 1,850 & 16.67 \\
\hline 5 & Mabibo & 1115 & 6,690 & & 6,690 & 100 \\
\hline 6 & Kawawa & 2925 & 17,550 & & 17,550 & 100 \\
\hline 8 & Kawe A & 1736 & 10,416 & 2604 & 7,812 & 75 \\
\hline 9 & Tandale & 1809 & 10,854 & & 10,854 & 100 \\
\hline \multirow[t]{3}{*}{10} & Mlimani & 1006 & 6,036 & 5030 & 1,006 & 16.67 \\
\hline & TOTAL & 14,661 & $87,966(73,305)$ & 17,884 & 70,082 & 79.67 \\
\hline & Percentages & & 100 & 20.3 & 79.7 & \\
\hline
\end{tabular}




\subsubsection{Drinking Water Access Points and Adequacy of Water Facilities in Public Primary Schools}

The study revealed that $72.4 \%$ of the pupils from the visited schools bring drinking water from home. Other pupils $(20 \%)$ accessed drinking water from standpipe within the school premises and the remaining $(6 \%)$ accessed water from rainwater storage tanks supplied using hand pumps. It was revealed that school teachers and their head teachers were often accountable to communities and government authorities for school matters relating to condition of classrooms, pupil attendance, and educational performance. However, school administration is often not held accountable for provision of safe drinking water, hand-washing facilities and soap, or adequate and clean sanitation facilities in the study area. This situation was also observed in a study carried to assess sanitation campaign in schools in Tanzania [3].

\subsubsection{Safe Handling of Water and Age of Water Supply Facilities}

Drinking water supplied to school should meet national standards and follow WHO drinking water quality guideline [24]. According to SWASH guideline (2010) recommends that if water is stored in school, containers should be clean and covered, and there should be a tap from the container or way to safely remove the water without contaminating it. However the study revealed that $40 \%$ of the public primary schools visited had ground storage tanks for storing water, but most of the storage tanks were not properly covered hence water become of poor quality.

The study also assessed age of the provided facilities where it was found that $42.8 \%$ of the school water supply facilities have been constructed within the past five years, $42.9 \%$ over ten years and $14.3 \%$ over twenty years. Most of the water supply facilities were not working because of aging and poor maintenance. Four schools out of ten schools sampled had piped water from the municipal system, but water supply facilities were not functioning effectively. School reports cost or lack of funds for repair and maintenance as reasons for not having water supply that were working. Given the big number of users, the researcher realized that the rate at which these facilities wear out was quit high a reason for malfunctioning. $60 \%$ of the school head teachers of all visited primary schools with water sources reported that they are repairing their water sources when they break down, but $40 \%$ of the schools reported that the repair is done by other body. Also, it was noted that all government schools had no fence the situation, which attracted other people to use water from school sources and hence increase water pressure and sometimes vandalism of the infrastructure.

\subsubsection{Child-Friendly Facilities}

In the study area three schools out of ten schools visited had children with physical disabilities, however, $92 \%$ of water facilities available do not favor pupils with physical disabilities, and they get help from their fellow pupils once they need to get water from the facilities. While this happens there is recommendation that water point design should be appropriate and accessible for small children and people with disability $[16,17]$.

\subsection{Sanitation Facilities and Hygiene facilities Available in Public Primary Schools}

Through observation the study revealed that $60 \%$ of schools visited use concrete cemented urinals and $40 \%$ of the schools had no urinals for boys, while for teachers only $10 \%$ of the schools had urinal. In those schools $90 \%$ with no urinal they use toilets for both defecation and urinating. Although, sanitation and water reports for the public primary schools indicated availability and fair distribution of sanitation facilities especially the latrines and urinals, through observation it was clear that the facilities in the study area were not in good condition. Besides some of the doors that had been fixed to ensure privacy had been broken and some had been completely removed.

\subsubsection{Technology Type}

Ventilated pit latrines were most common sanitation technology found in primary schools of Kinondoni municipality $(60 \%)$. In the study area other schools have some other types of improved sanitation technology like flush toilet $(10 \%)$ and $20 \%$ had unimproved sanitation such as pit latrines. As for urinals, they use locally made cemented urinals, while $1.2 \%$ of the pupils reported that in their schools, the bush is used as urinals.

\subsubsection{Cleanliness of Sanitation Facilities}

A sizeable proportion (3.6\%) of pupils rated toilets as clean and $7.3 \%$ rated urinal facilities as good. A proportional of $67.7 \%$ rated that the general cleanliness of the toilets was poor. Generally speaking the majority of the sanitation facilities were unclean which discourage the pupils using them comfortably. Few teachers and pupils have conditioned themselves to avoid urinating and defecation at school.

\subsubsection{Adequacy of Sanitation Facilities}

The findings revealed inadequacy of both toilets and urinals as presented by a sizeable proportion of $46.6 \%$ for toilets and $47.1 \%$ for the urinals and $43.2 \%$ for hand washing facilities. Generally, the findings reveal that the urinal facilities are inadequate as compared to the toilet facilities. Through observation the study revealed that majority $90 \%$ of the schools visited in the study area had no hand washing facilities that are either installed within the toilet unit or outside near the toilet units. $20 \%$ of schools had more than 100 pupils per drop hole and $6 \%$ of schools had no latrines at all. The national averages for the number of pupils per toilet/ urinal which is recommended by the Ministry of Education and Vocational Training are one toilet per 20 pupils for girls and one toilet per 25 pupils for boys and plus one Urinal per 50 pupils for boys. Also it was revealed that $96 \%$ of schools had no facilities that are suitable or accessible to children with disabilities. $52 \%$ of girls' latrines did not have doors providing dignity and privacy. This finding is not new as it was reported by Sommer, (2010) what is bothering is the persistence of the situation despite many efforts globally and 
locally $[19,3]$.

During the survey the research revealed that the numbers of stances available in schools were not enough for the increased number of pupils as it was reported by key informant interview;

"We have serious shortage of water points here compared to the number of users. The problem is exacerbated by lack of fence whereby people from nearby community fetch water from school especially during weekend and holidays and sometimes they vandalize the service (Kinondoni, Head of school in sampled school, $23^{\text {rd }}$ May 2013.)".

Generally speaking, the findings reveal that the sanitation facilities are inadequate compared to the number of pupils enrolled at schools. The deficit of toilets for both boys and girls are $81.8 \%$ and $80.3 \%$ respectively in the study area.

The values presented above indicate big deficits of sanitation facilities in the ten sampled schools of Kinondoni District. The study revealed that poor state of WASH facilities was attributed to the low prioritization by both government and communities. As one of the interviewed school teacher noted;

"I have been dealing with health issues in school for a long time now, but I tell you that, little attention is given to sanitation issues by both parents and the government. Both parents and government care about pupil's performance not school environment including sanitation. The only thing they care related to sanitation is removal of solid waste because everyone can observe (Kinondoni; Anonymous health school teacher on $12^{\text {th }}$ May 2013)."

Poor resource management and limited financial accountability for funds allocated by local government and contributions to school committees from parents, were also contributing factors. On the other hand, national and international NGOs, the private sector and development partners were working without proper coordination.

\subsubsection{Utilization of the Available Sanitation Facilities}

The study revealed that a relative big percentages (53\%) of pupils reported that they are not using school's sanitation facilities. Others (13.4\%) said that in rare cases they use the sanitation facilities because they have no alternative. Only $33.3 \%$ indicated that they had no problem of using their schools sanitation facilities. Some of the key informants blamed the poor cleanliness of the facilities to big number of users and pupils who come from poor backgrounds without proper sanitation and hygiene practices. It was observed that in some of the latrines, walls and toilet bowls were stained with fecal matters revealing poor cleanliness. This was common for the boys' toilets. For the girls, urine was found to be flooding the floors, these practices were said to have caused intolerable smell in the sanitation facilities.

A proportions of $60.7 \%$ of pupils responded that no hand washing facilities were installed in sanitation facilities at their school while $15.7 \%$ reported that they do wash after leaving the toilets and urinals. Discussing with the key informants it was revealed that most of the sanitation facilities at schools were not provided with hand washing facilities and where they were installed water problems at schools had led to poor usage of the facilities. Also other key informant interviewed reported that lack of toilet manners and lack of sanitation and hygiene knowledge lead to poor utilization of the hand washing facilities that are provided.

\subsubsection{Accessibility of Sanitation Facilities}

A relative big percentage (60\%) of sampled schools had boys' and girls' toilets attached to the classrooms buildings, while the rest $40 \%$ had their toilets separated from classrooms. $66.7 \%$ of schools had both male and female teacher toilet within the school buildings. Generally most of the schools visited had the school toilets within the appropriate distances from the classroom.

\subsubsection{Hygiene and Maintenance of Toilet Facilities}

Toilets must be clean to be user friendly. The hygiene conditions of toilet facilities were assessed. There were remarked differences in terms of sanitary condition of the toilet facilities between pupils' and teachers' toilets. Majority $(90 \%)$ and $(80 \%)$ for both boys and girls toilets facilities were often dirty. While $67.3 \%$ of schoolteachers' toilets were found to be clean and the remaining $33.3 \%$ were dirty. It was revealed that $20 \%$ of the schools visited hired labor to clean the toilet facilities, while $80 \%$ of the schools used pupils to clean both teachers' and pupils' toilet facilities. Some schools had adopted a duty roster system, which involved all pupils in cleaning of toilets. At most all schools that were visited, the cleaning of toilet facilities were done as a punishment to those pupils who misbehaved in class or those who committed minor offences while at school. This was mentioned during the interviews with school health teacher. Using toilet cleaning, as punishment is not good as it may instill habit of hating toilet cleaning because of associating it with punishment. As part of hygiene and maintenance of pupil's toilets cleanness, the following issues were assessed.

(a) Anal Cleansing Materials

It was evident that the majority $(90 \%)$ of primary schools did not have anal cleansing materials placed in the toilets. In most of the schools $(80 \%)$ visited only teachers' toilets were provided with bucket with full of water as the anal cleansing materials. About $82 \%$ of pupils use pieces of papers as anal cleansing materials after defecating. This is a problem because they sometimes tear their exercise books and hence miss notes for reference latter on. Only $10 \%$ use water and $8 \%$ use other material. The use of paper and other materials may lead to toilet blockage especially for flushing toilets.

(b) Toilet Facilities Cleaning Materials

Detergents soap, brooms, gloves, gumboots and water were used for the cleaning of the toilet facilities. The study observed that $79 \%$ of the schools in the study area had shortage of cleaning materials. Insufficient funds were often mentioned as the reason for the poor SWASH activities. The frequency of cleaning varied from school to school, and nearly three quarters $(74 \%)$ of the schools surveyed reported that it was done at least once a day, but most often without cleaning detergents.

(c) Handwashing Facilities 
Only $10 \%$ of surveyed schools had hand washing facilities equipped with running water, the remaining $90 \%$ had no facilities and no running water. However, in most of the schools $70 \%$ had water basins with bucket filled with water for teachers' toilets. It was very unfortunate that despite the success of installing hand-washing facilities in some schools, neither school had soap on the day the survey was conducted. The reason given by one of the schools for lack of soap provision was that the school management had no money to buy soap to supply to all pupils and even if the soap is bought it will be stolen.

(d) Waste Disposal Facilities and Refuse Disposal

Both liquid and solid waste management remain to be a challenge in many schools. Facilities for waste management such as waste disposal bins were hardly provided in school compound. The findings revealed that dustbins were lacking in $80 \%$ of the schools surveyed upon observation. Only $20 \%$ of the schools visited had refusal bay. Moreover the study revealed that the dustbins in most schools were not covered.

Methods of solid waste disposal were also observed. Although the school sanitation guidelines discourage burning refuse, the study found that relative big percentages $(70 \%)$ of the schools burnt their solid waste within the school compound. $20 \%$ of the surveyed schools throw on the garbage dump (refusal bay) within the school compound and $10 \%$ of the schools bury their solid waste within the school compounds.

\section{Conclusion}

Although the government primary schools in Kinondoni Municipality own the variety of water sources and sanitation facilities the study unveiled existing of inadequate water supply and sanitation facilities, poor condition of WASH facilities, inadequate financial capacity; weak community support; poor operation and maintenances of the existing facilities. Also the study revealed unhygienic of the facilities, overcrowded, low priority of WASH activities by both governments and communities whereby vandalism from unintended users was reported. Lack of fencing among schools were reported as a problem in management of the sanitation facilities and it was also revealed low pupils engagement in WASH activities whereby in few cases it was taken as punishment among pupils who misbehave during school sessions.

\section{Recommendations}

Basing from the above conclusion the study recommends to the government and public as whole to give high priority to water and sanitation issues for primary schools. Also the government in collaboration with the community should increase water reliability at schools through multiple sources (water tape, deep wells and rooftop rainwater harvesting), which are thought to be the best solution. Rooftop rainwater harvesting is expected to instill new attitudes toward using rooftop rainwater harvesting for domestic uses as well for controlling down stream storm water flooding during rain season. It is recommended that parents and pupils should be involved in SWASH program awareness creation campaigns as well to consider economic and cultural appropriateness facilities. Also, teachers are asked to avoid punishing pupils by using toilet cleaning at schools. Finally, community should collaborate with government to ensure that all primary schools are fenced and employ qualified security guards.

\section{References}

[1] Bartlett, S., (2003). Water, sanitation and urban children: The need to go beyond "improved" provision. Environmental Urban. 2003, Volume 15, 57-70.

[2] Cairncross, S., Jamie Bartram, J., Cumming, O., Brocklehurst, C., (2010). Hygiene, Sanitation, and Water: What Needs to Be Done? November 2010. Vol. 7. Issue 11. e1000365

[3] Chitty, Alexandra, Roma, Elisa, Durrans, Sophie, (2017). Policy Brief. Process Evaluation of Tanzania's National Sanitation Campaign. Sanitation, Hygiene Applied Research for Equity (SHARE). London.

[4] IRC, (2004). Sustainability of Hygiene Behaviour and the Effectiveness of change interventions: Lessons learned on research methodologies and research implementation from a multi-country research study, International Water and Sanitation Centre.

[5] Kasper, Shaina M. Pomerantz (2013). Conflicting Discourses of Participatory Postdevelopment in Community-Led Total Sanitation. Honours Projects. Paper 9 at http://digitalcommons.macalester.edu/envi_honors/9 [Retrieved 14th July 2013]

[6] Mara, D., \& Alabaster, G., (2008). A new paradigm for lowcost urban water supplies and sanitation in developing countries. Water Policy. Vol. 10 (2). pp. 119-129.

[7] Msuya, S. Mbonea, (2016). Higher learning institutions walk the talk! Assessing the health of the environment! Managing Development in Africa. Volume 1, Issue 1, pp. 73-87.

[8] Msuya, S., \& Kamanzi, A., (2017). Sanitation in practice: an experience of traditional pit latrine use in Tanzania. Managing Development in Africa. Volume 2 Issue 2, pp. 137-159.

[9] Sommer, M., (2010). Where the education system and women's bodies collide: The social and health impact of girls' experiences of menstruation and schooling in Tanzania. Journal of Adolescence. Volume 33, Issue 4, August 2010, pp. 521-529.

[10] UN, (2015a) The Millennium Development goals Report 2015. The UN. New York.

[11] UN, (2015b). Transforming our world: the 2030 Agenda for Sustainable Development. United Nations. New York.

[12] UNICEF, (2010). Water, Sanitation and Hygiene Report. The UN. New York.

[13] UNICEF, (2017). Water, Sanitation and Hygiene. At, https://www.unicef.org/wash/ Accessed on $27^{\text {th }}$ October 2017

[14] UNICEF, WaterAid, and SNV., (2011). School WASH Mapping Report. Dar es Salaam: United Nations Children's Fund, Water Aid, and SNV. 
[15] UNICEF/WHO, (2012). Progress on Sanitation and Drinking Water, Joint Monitoring Programme 2012 Update. http://w.w.w.wssinfo.org. [Retrieved $10^{\text {th }}$ June 2013]

[16] URT, (2010) National Guideline for School Water, Sanitation and Hygiene (SWASH) in Tanzania - 1st Draft for Piloting \& Consultation United Republic of Tanzania, Dar es Salaam.

[17] URT, (2012) Ministry of education and Vocational Training National Strategic Plan for School Water, Sanitation and Hygiene (swash) 2012 -2017. Dar es Salaam.

[18] URT, (2013). Population and Housing Census. Population Distribution by Administrative Areas. Dar es Salaam. Government Printers.

[19] URT, (2014). Education for All 2015 National Review Report: United Republic of Tanzania. Ministry of Education and Vocational Training. Dar es Salaam.

[20] URT, (2016). Primary School Enrolment by Sex and Age Datasets. President's Office-Regional Adminstration and Local Government (PORALG). Government Printers. Dar es Salaam.

[21] WaterAid and UNICEF, (2009) Water, Sanitation and Hygiene report of 16 districts in Tanzania (Unpublished report) Dar es Salaam.

[22] WaterAid, (2011). "Wash Sector Overview" at $\mathrm{http} / / /$ tanzania.wateraid.org/about-us/wash-sector-overview [Retrieved on 12th May 2012]

[23] WaterAid, (2017). Water, sanitation and hygiene in schools.http://wateraidindia.in/water-sanitation-and-hygienein-schools/ Accessed on $27^{\text {th }}$ October 2017

[24] WHO (2009) Water, sanitation and Hygiene Standards for Schools in Low-cost Settings Edited by John Adams, Jamie Bartram, Yves Chartier, Jackie Sims. Geneva.

[25] WHO/UNICEF, (2015). Lack of sanitation for 2.4 billion people is undermining health improvements. Final MDG Progress report on water and sanitation released. http://www.who.int/mediacentre/news/releases/2015/jmpreport/en/ [Retrieved $11^{\text {th }}$ May 16]

[26] Young, Johanna, (2017). School-Based Water, Sanitation and Hygiene Interventions. An Effective Means to Promote Hygienic Behaviour Amongst School Children Kaleidos Research. Amsterdam. 